\title{
Optimal Control Problem of Converter Steelmaking Production Process Based on Operation Optimization Method
}

\author{
Jun Zhang \\ State Key Laboratory of Synthetical Automation for Process Industries, Northeastern University, Shenyang 110819, China \\ Correspondence should be addressed to Jun Zhang; wtuyss2000@163.com
}

Received 3 September 2014; Revised 13 January 2015; Accepted 14 January 2015

Academic Editor: Peng Shi

Copyright (c) 2015 Jun Zhang. This is an open access article distributed under the Creative Commons Attribution License, which permits unrestricted use, distribution, and reproduction in any medium, provided the original work is properly cited.

\begin{abstract}
Dynamic operation optimization has been utilized to realize optimal control problem for converter. The optimal control indicator is determined via current state of converter smelting production process, and the set values of operation variable would control converter production. Relationship between various operating variables, current temperature, and carbon content is constructed through operation analysis of a great deal of actual production data; then, the dynamic optimal control indicator is derived from historical excellent smelting data; finally, the dynamic operation optimization model is built by taking the minimum deviation between the current data-molten steel temperature and carbon content-and optimal data which are determined by the optimal control indicator as objective function. DE (differential evolution) with improved strategy is used to solve the proposed model for obtaining the set values of each operating variable, which is beneficial for further control. Simulation of actual production data shows the feasibility and efficiency of the proposed method. That proved that the proposed method solves the optimal control problem of converter steelmaking process as well.
\end{abstract}

\section{Introduction}

The optimal control of converter steelmaking plays an important role in ensuring the steel quality.

The optimal control problem is considered in a dynamic system or a movement process. The optimal control indicator should be gotten when the motion transferred from an initial state to a specified goal state.

The general view of a converter is shown in Figure 1. Converter smelting production and the main control stage are shown in Figure 2. A certain amount of solid scrap and desulphurization molten iron is poured into the furnace. Then, oxygen (F011) is blown into the furnace through the lance which is entered from the top of furnace. The auxiliary materials, such as limestone and dolomite (F001-F007), are added. At the same time, the mixture of nitrogen and argon (F012) is blown from the bottom to stir the molten iron. Hot metal surface contacted with oxygen would form molten bath. The elements, such as carbon, silicon, and manganese, should be removed when it reached the $85 \%$ of blowing cycle, and molten steel temperature and component information would be sampled by a sublance. According to the deviation values between the information and target end point, the amount of deputy auxiliary materials and oxygen could be evaluated. The dynamic blowing stage would start. At the end of the stage, the sublance would take a sample again. If the temperature and composition requirements achieved our preaimed values, take an alloying treatment of steel or tap steel. Otherwise, it has to continue blowing till it meets the requirements.

One of the optimal control problems in BOF (basic oxygen furnace) steelmaking process is how to set the control variable values and make the dynamic optimal control indicator be the best one. In order to solve this optimal control problem, the dynamic operation optimization method is introduced in BOF steelmaking process control.

The operation optimization for iron-steel smelting process is to conduct an in-depth study of the production process based on the mathematics and physics statistics. It could figure out the input-output relations by analyzing and summarizing the relationship between operating parameters and product control indicators and optimize the production process according to these input-output relations. In other words, aiming at enhancing the technology and performance with the existing technical process and production equipment, the operation optimization for iron-steel smelting process is to 


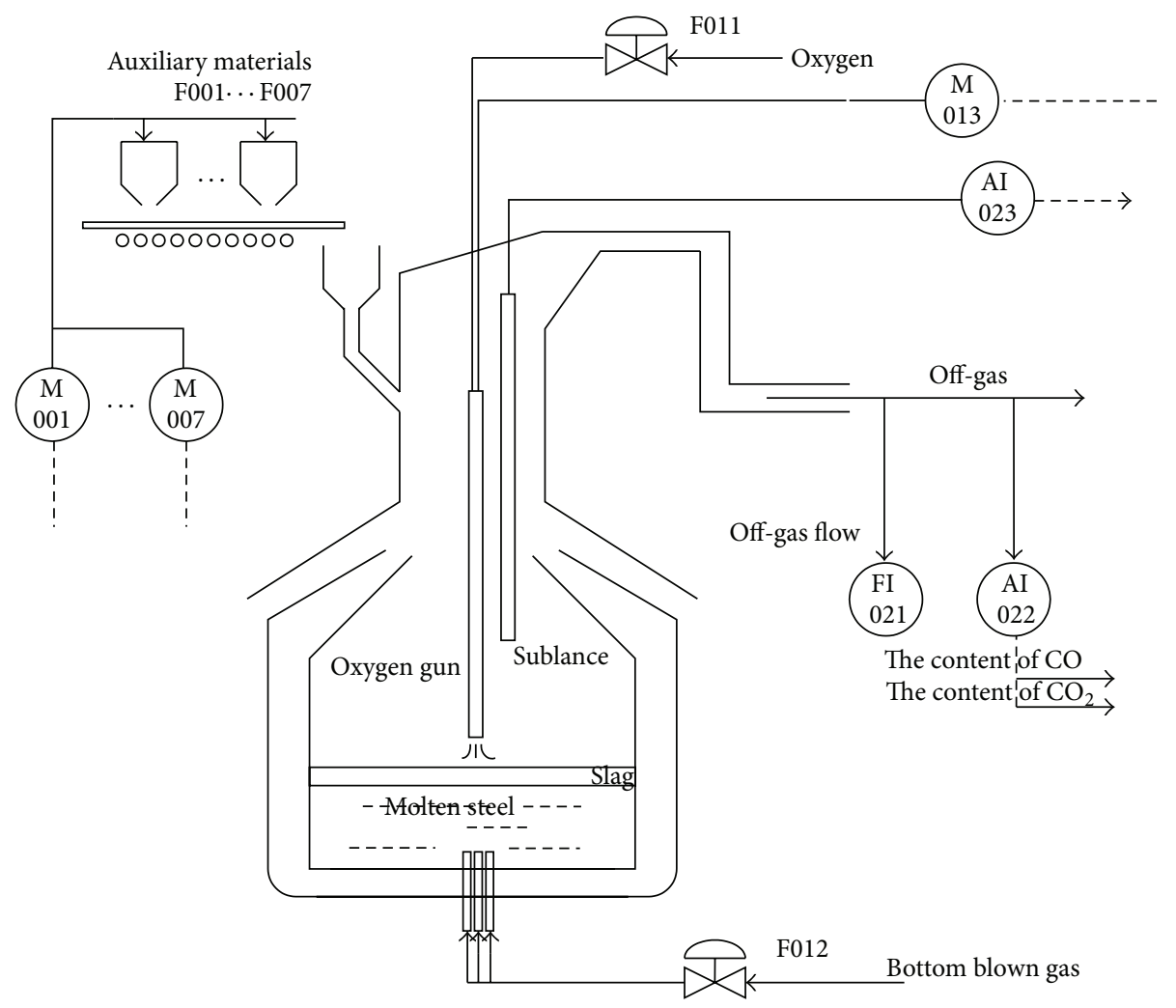

FIGURE 1: General view of a converter.

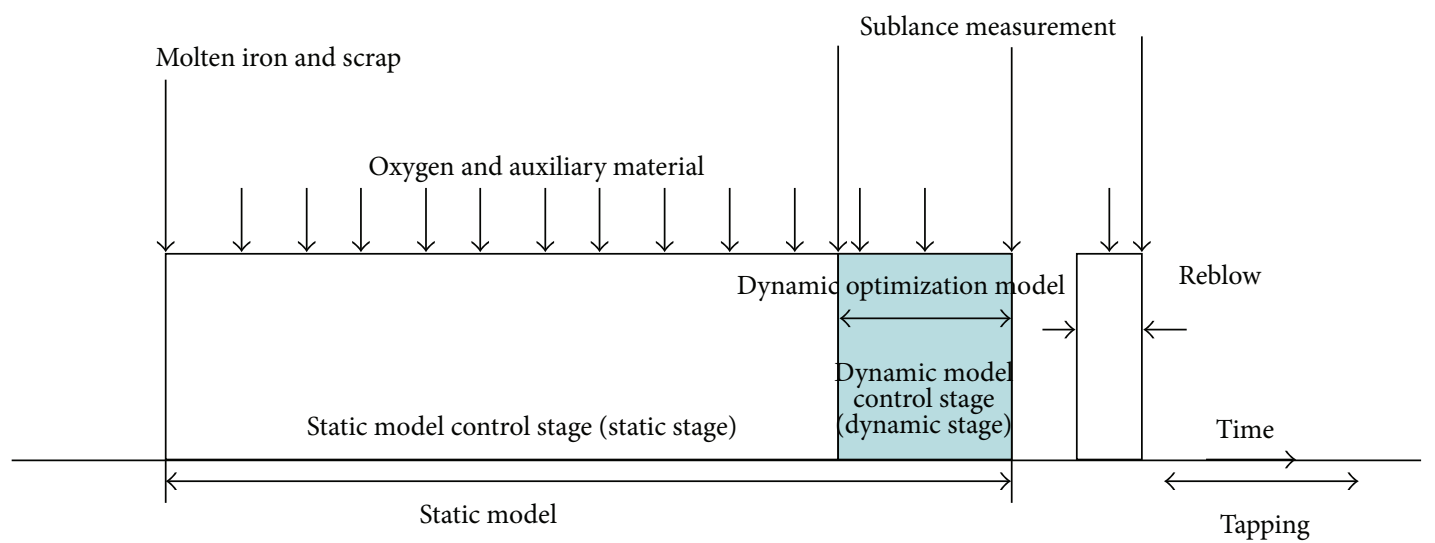

FIGURE 2: Converter steelmaking production and main control stage.

keep the production process in an optimal operation state by setting or adjusting production process parameters when any changes happen to the environment variables or product control indicators indicated by the real-time information monitoring system. Consequently, the inner quality would be increased, and the cost and energy consumption are decreased. Operation optimization for the converter smelting process shows great theoretical and practical meanings for improving the production operation management.

The concept of real-time operation optimization was proposed in the 1950s and was first used in the ethylene production in the 1980s. An improved real-time operation optimization method is proposed by Marlin and Hrymak [1]. And Yip and Marlin [2] used the method to improve whole production efficiency. Peters et al. [3] presented a realtime operation optimization control method in the chemical production batch control process; this method is also applicable to nonlinear systems. Adetola and Guay [4] proposed a mix real-time operation optimization and prediction control method to solve nonlinear chemical system. Alvarez and Odloak [5] proposed an improved method based on the Adetola method to strengthen the stability and decrease the uncertainty. de Souza et al. [6] used real-time optimization method to directed model predictive control for control 
accuracy. The ethanol amine reaction process was optimized using operation optimization concept [7]. Wellons et al. [8] proposed the offline nonlinear optimization operating system applied in Mobil Oil Corp. in Beaumont and Texas Refinery. Eliceche et al. [9] proposed an operation optimization method to optimize the material inputting of ethylene production. Petracci et al. [10] proposed an optimal operation method to improve an ethylene plant utility system. Shao et al. [11] applied the operation optimization to improve the production efficiency and stability in the production process of acetaldehyde. Lu [12] proposed a dynamic operation optimization scheme to improve the overall efficiency of production, in which operating variables can be determined from a particular point in prediction in time domain, and the point would not be a steady point. Bonvin and Srinivasan [13] would focus on the dynamic operation optimization problem of uncertain factors to the uncertainty of model parameters, which reduced the computational complexity of model. Biegler [14] presented a new model of dynamic operation optimization to enrich the means of control in the petrochemical field, and the achievement has aroused a great concern among the industries. Tang et al. [15] studied an integrated charge batching and casting width selection problem arising in the continuous casting operation of the steelmaking process and developed a column generationbased branch-and-price solution approach to obtain optimal solutions. Tang et al. [16] present a mathematical model, based on the just-in-time idea, for solving machine conflicts in steelmaking-continuous casting production scheduling in the computer integrated manufacturing system environment. Tang et al. [17] constructed a novel integer programming formulation with a separable structure and developed a solution methodology combining Lagrangian relaxation, dynamic programming, and heuristics.

In the iron and steel smelting production process, data analysis methods also played a key role. Wu et al. [18] proposed a real-time detection model based on thermodynamic equilibrium and the improvement of gas analysis model to give an online prediction of the temperature in converters. Wen et al. [19] proposed a neural network model to forecast the endpoint station of converter based on radiation information and image information. Xu et al. [20] proposed a model of basic oxygen furnace (BOF) endpoint prediction based on spectrum information of the furnace flame with support vector machine to predict the $\mathrm{BOF}$ steelmaking endpoint temperature and carbon content value. Han et al. [21] used support vector machine algorithm to predict the amount of required oxygen of the converter production ensuring the control of converter smelting.

Operators have accumulated considerable experiences in the control of converter production operations and made great achievements. However, due to many factors, such as various production process constraints, characteristics of high temperature, short cycle in smelting process, and the speed and complexity in physical and chemical reaction, realtime detection information is difficult to obtain accurately. So, it is difficult to establish the optimal control model.
To solve the above optimal control problem, an operation optimization method in BOF steelmaking process is proposed. In this method, the time and weight of adding limestone, dolomite, and other auxiliary materials, the amount of blowing oxygen, bottom blowing gas at each moment, and the control mode of oxygen lance are regarded as control variables. First, a large number of actual steel production data are collected which would be used to create a dynamic phase reference data repository. With data analysis method, a forecasting model of furnace temperature and carbon content of the liquid steel is established. Next, cluster analysis on the reference furnace information base is performed. Determine reference value control movements by detecting temperature in the oven and carbon content of the molten steel. In addition, based on the requirements for the smelting production process constraints, an optimization model is built to minimize the deviation between the actual data (oven temperature and carbon content of the molten steel) and the reference data, which is composed by dynamic value. Finally, intelligent optimization algorithm is used to solve the model and get the best value of the control parameter. The method in this paper can grasp the situation of BOF steelmaking process intuitively and comprehensively. Figure 3 shows the operation optimization method in BOF steelmaking process.

The rest of the paper is organized as follows. First, the data analysis method is briefly described in Section 2. Next, Section 3 introduced the real-time predictive method. The dynamic operation optimization model based on data analytics is introduced in Section 4. Then, in Section 5, an improvement DE algorithm is proposed to solve the dynamic operation optimization model. In addition, in order to demonstrate the effectiveness of the proposed algorithm in the actual problem, a lot of experiments have been done. Comparable results with other methods are shown in Section 6. Finally, conclusions of the work and future work are presented in Section 7.

\section{Getting Data and Establishing Elite Furnace Data Set}

In this paper, the data are collected from the real iron and steel plant. The flame analyzer and the flue gas analyzer need to be installed on the steel converter. Flame temperature and composition of flue gas are measured. The throwing probe is used to detect temperature and carbon content in the molten steel. The time interval of measuring is 15 seconds. The operator could judge a better result, by virtue of his/her experiences, ranging from the actual temperature of the furnace, which is measured by flame analyzer, to temperature of the flue gas analyzer. In three months, a total of 1200 experiments are done, and data are obtained from 380 furnaces. We have deleted some abnormal data from the obtained data.

The temperature and carbon content value will be recognized and written into the data set, and then the most matching converter information will be selected to be the target value including the input condition, the actual tapping temperature, and the carbon content of the liquid steel. An elite furnace date set would be established by these data. 


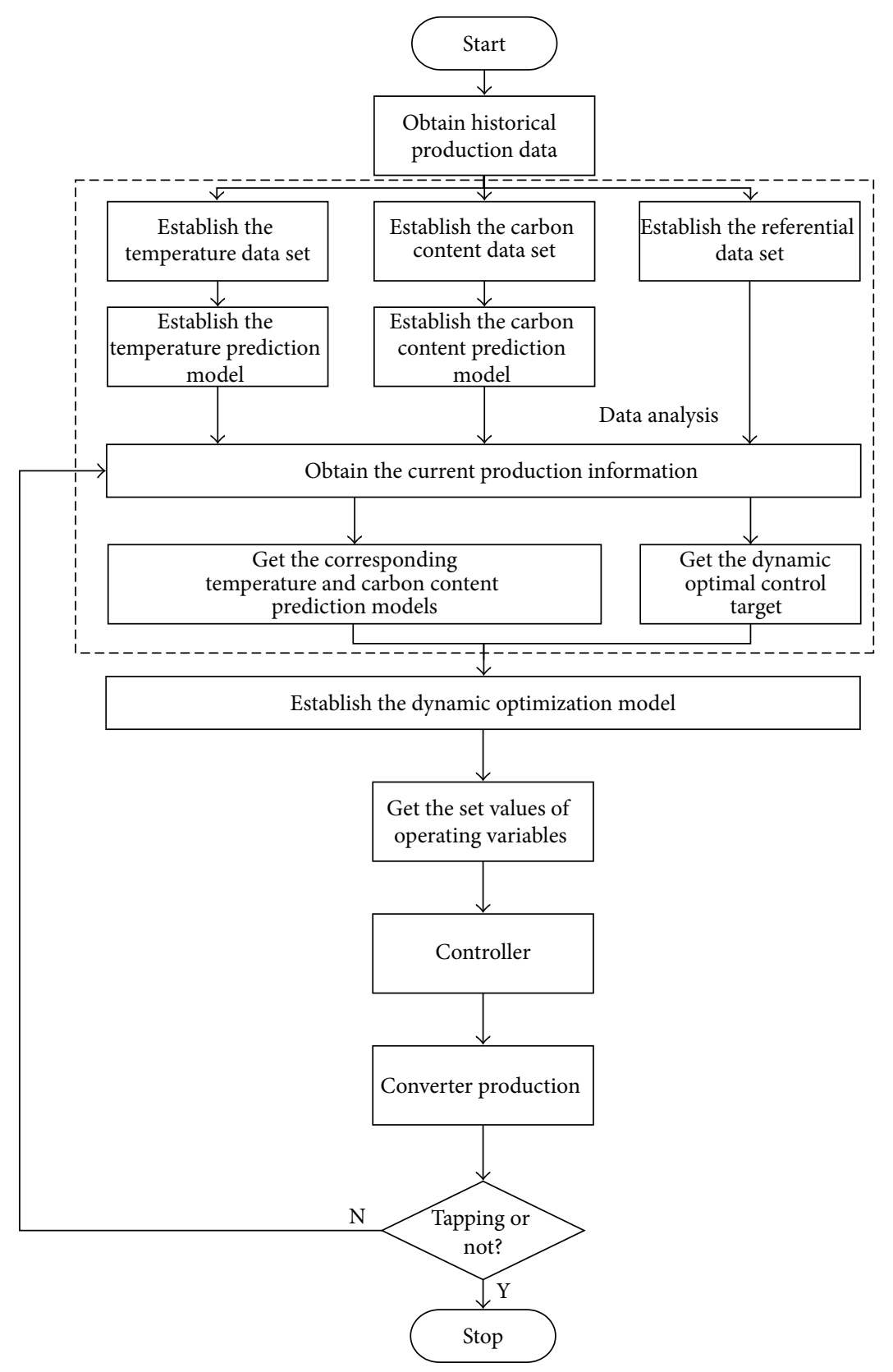

FIGURE 3: The operation optimization method in BOF steelmaking process.

\section{Real-Time Predictive Model}

3.1. The Predictive Algorithm. To verify the objective of the problem, a PSO (particle swarm optimization) algorithm would be used to optimize the parameters and root mean squared error would be the statistical evaluation index. The process of optimizing the LSSVM (least squares support vector machine) [22] parameters with IPSO (improved particle swarm optimization) is described as follows.

Step 1. Data preparation: training sets and testing sets are, respectively, represented as train data and test data.
Step 2. Initialization: generate the initial position and velocity of each particle randomly ( $\gamma$ and $\sigma$ are the parameters for LSSVM). Set the related parameters of IPSO method, and then perform the training process from Steps 3 to 7 .

Step 3. Determine the number of iterations.

Step 4. Fitness evaluation: this paper used the fitness function to evaluate the quality of each particle, and it must be calculated before searching for the optimal values of the LSSVM parameters. 
Step 5. Termination condition checking: if the stopping criterion satisfies the maximum iterations, go to Step 7. Otherwise, go to Step 6.

Step 6. Particle update: update the velocity and position value of each particle according to (1), and then generate the new particles; go to Step 3:

$$
\begin{gathered}
v_{i d}(t+1)=k *\left(w v_{i d}(t)+c_{1} r_{1}\left(\text { pbest }_{d}(t)-x_{i d}(t)\right)\right. \\
\left.+c_{2} r_{2}\left(\text { gbest }_{d}(t)-x_{i d}(t)\right)\right) \\
+c_{3} r_{3}\left(\left(\frac{\text { pbest }_{d}(t) * \text { gbest }_{d}(t)}{\text { pbest } \left._{d}(t)+\text { gbest }_{d}(t)\right)}\right)-x_{i d}(t)\right) \\
x_{i d}(t+1)=x_{i d}(t)+v_{i d}(t+1) .
\end{gathered}
$$

Step 7. Stop the training procedure: obtain the optimized parameters $\gamma$ and $\sigma$.

3.2. Prediction Model and Correction Formula. Because the temperature and carbon content of outputs are changed in a dynamic process, inputs are regarded as a dynamic variable. Besides, input variables include the weight of the molten steel $\left(\mathrm{H}_{\mathrm{in} 1}\right)$, adding weight of the scrap $\left(\mathrm{H}_{\mathrm{in} 2}\right)$, the content of the blowing oxygen in the reaction process $(\mathrm{O}(t))$, the content of bottom blown gas in the reaction process $(\mathrm{N}(t))$, carbon content of the molten steel at previous time $\left(\mathrm{S}_{\mathrm{C}}(t)\right)$, the height of the oxygen lance at the current moment $\left(V_{1}(t)\right)$, the height of the molten pool at the current moment, flue gas flow in the reaction process $(\mathrm{GF}(t))$, the level of carbon monoxide in the reaction process $(\mathrm{CO}(t))$, the level of carbon dioxide in the reaction process $\left(\mathrm{CO}_{2}(t)\right)$, the temperature of the molten steel at previous time $(T(t))$, and extra seven kinds of supplementary materials $\left(\mathrm{H}_{I}(t)\right)$. The number of input variables is seventy and the number of output variables is only one.

The molten steel temperature prediction model is given as follows:

$$
\begin{aligned}
& Y_{T}^{\prime}(t+1) \\
& =\operatorname{LSSVM}_{1}\left\{T(t), \mathrm{S}_{\mathrm{C}}(t), \mathrm{H}_{I}(t), \mathrm{N}(t), \mathrm{O}(t),\right. \\
& \left.\quad \mathrm{GF}(t), \mathrm{CO}(t), \mathrm{CO}_{2}(t), V_{1}(t), \mathrm{H}_{\mathrm{in} 1}, \mathrm{H}_{\mathrm{in} 2}\right\} .
\end{aligned}
$$

The carbon content of molten steel prediction model is given as follows:

$$
\begin{aligned}
& Y_{\mathrm{C}}^{\prime}(t+1) \\
& =\operatorname{LSSVM}_{2}\left\{T(t), \mathrm{S}_{\mathrm{C}}(t), \mathrm{H}_{I}(t), \mathrm{N}(t), \mathrm{O}(t),\right. \\
& \left.\quad \mathrm{GF}(t), \mathrm{CO}(t), \mathrm{CO}_{2}(t), V_{1}(t), \mathrm{H}_{\mathrm{in} 1}, \mathrm{H}_{\mathrm{in} 2}\right\} .
\end{aligned}
$$

The current temperature estimation model is given as follows:

$$
\begin{aligned}
& T(t)=\operatorname{LSSVM}_{1}\left\{T(t-1), \mathrm{S}_{\mathrm{C}}(t-1), \mathrm{H}_{I}^{\prime}(t-1), \mathrm{N}^{\prime}(t-1),\right. \\
& \mathrm{O}^{\prime}(t-1), \mathrm{GF}(t-c), \mathrm{CO}(t-c), \\
& \left.\mathrm{CO}_{2}(t-c), V_{1}^{\prime}(t-1), \mathrm{H}_{\mathrm{in} 1}, \mathrm{H}_{\mathrm{in} 2}\right\} \text {. }
\end{aligned}
$$

The current carbon content estimation model is given as follows:

$$
\begin{aligned}
& \mathrm{S}_{\mathrm{C}}(t) \\
& =\operatorname{LSSVM}_{2}\left\{T(t-1), \mathrm{S}_{\mathrm{C}}(t-1), \mathrm{H}_{I}^{\prime}(t-1), \mathrm{N}^{\prime}(t-1),\right. \\
& \mathrm{O}^{\prime}(t-1), \mathrm{GF}(t-c), \mathrm{CO}(t-c), \\
& \left.\mathrm{CO}_{2}(t-c), V_{1}^{\prime}(t-1), \mathrm{H}_{\mathrm{in} 1}, \mathrm{H}_{\mathrm{in} 2}\right\}
\end{aligned}
$$

where $T(t-1)$ is the temperature of molten steel in time $t-1$; $\mathrm{S}_{\mathrm{C}}(t-1)$ is the carbon content of molten steel in time $t-1$; $\mathrm{H}_{I}^{\prime}(t-1), \mathrm{N}^{\prime}(t-1), \mathrm{O}^{\prime}(t-1)$, and $V_{1}^{\prime}(t-1)$, respectively, are the amount of blowing oxygen, lance mode, the amount of bottom blowing gas, and bottom blowing mode at time $t$ 1. $\mathrm{GF}(t-c), \mathrm{CO}(t-c)$, and $\mathrm{CO}_{2}(t-c)$ are, respectively, the amount of flow of flue gas and $\mathrm{CO}$ and $\mathrm{CO}_{2}$ content in flue gas at time $t-c . c$ is the corresponding time delay correction parameter.

By comparing flue gas flow rates, $\mathrm{CO}$ and $\mathrm{CO}_{2}$ of flue gas with the values are specified by the optimization control indicator. If relative error $e(t)$ is less than $6 \%$, skip the error correction; otherwise, start the error correction: the correction value of molten steel temperature is given as $Y_{T}^{\prime \prime}(t+$ $1)=Y_{T}^{\prime}(t+1) \times\left[1+r_{11} \times e(t)\right]$. The correction value of molten steel's carbon content is given as $Y_{\mathrm{C}}^{\prime \prime}(t+1)=Y_{\mathrm{C}}^{\prime}(t+1) \times[1+$ $0.5 \times r_{12} \times e(t)$ ], where $r_{11}$ and $r_{12}$ are two random numbers in $[-1.0,1.0]$.

\section{Dynamic Operation Optimization Model}

4.1. The Dynamic Optimal Control Indicator Value. The optimal temperature indicator is current molten steel temperature optimal heating rate. The current dynamic optimum decarburization indicator is the optimal decarburization rate.

By comparing current temperature and carbon content of molten steel, the addition of hot metal and scrap, the aim temperature, and carbon content of molten steel, the most similar furnace set as reference furnace would be selected from the elite furnace data set. Current molten steel temperature optimal heating rate of reference furnace is $(T(t+$ $1)-T(t)) / \Delta t$. The optimal decarburization rate is $\left(S_{C}(t)-\right.$ $\left.\mathrm{S}_{\mathrm{C}}(t+1)\right) / \Delta t$. And the reference data are

$$
\begin{gathered}
T(t+1)-T(t)=\sum_{j=1}^{1}\left(T_{j}(t+1)-T_{j}(t)\right), \\
\mathrm{S}_{\mathrm{C}}(t)-\mathrm{S}_{\mathrm{C}}(t+1)=\sum_{j=1}^{1}\left(\mathrm{~S}_{\mathrm{C} j}(t)-\mathrm{S}_{\mathrm{C} j}(t+1)\right) .
\end{gathered}
$$

4.2. Dynamic Operation Optimization Model for Optimal Control Problem. To minimize the deviation between the current temperature of the liquid steel and the reference value decided by the optimization control indicator and minimize the deviation between the current carbon content and the reference data, we establish the multiobjective realtime operation optimization model. 
Optimization objective is as follows:

$$
\begin{aligned}
& \operatorname{Min}\left(Y_{T}^{\prime \prime}(t+1)-Y_{T}(t+1)\right)^{2}, \\
& \operatorname{Min} \xi\left(Y_{C}^{\prime \prime}(t+1)-Y_{C}(t+1)\right)^{2},
\end{aligned}
$$

Constraints are the following:

$$
\begin{aligned}
& Y_{T}(t+1)=T(t+1), \\
& Y_{\mathrm{C}}(t+1)=\mathrm{S}_{\mathrm{C}}(t+1), \\
& Y_{T}^{\prime \prime}(t+1)=Y_{T}^{\prime}(t+1) \times\left[1+r_{11} \times e(t)\right], \\
& Y_{\mathrm{C}}^{\prime \prime}(t+1)=Y_{\mathrm{C}}^{\prime}(t+1) \times\left[1+0.5 \times r_{12} \times e(t)\right] \text {, } \\
& \mathrm{H}_{I}(t)_{\min } \leq \mathrm{H}_{I}(t) \leq \mathrm{H}_{I}(t)_{\max }, \\
& \mathrm{N}(t)_{\min } \leq \mathrm{N}(t) \leq \mathrm{N}(t)_{\max }, \\
& \mathrm{O}(t)_{\min } \leq \mathrm{O}(t) \leq \mathrm{O}(t)_{\max }, \\
& V_{1}(t)_{\min } \leq V_{1}(t) \leq V_{1}(t)_{\max }, \\
& Y_{T}^{\prime}(t+1)=\operatorname{LSSVM}_{1}\left\{T(t), \mathrm{S}_{\mathrm{C}}(t), \mathrm{H}_{I}(t)\right. \text {, } \\
& \mathrm{N}(t), \mathrm{O}(t), \mathrm{GF}(t), \mathrm{CO}(t), \\
& \left.\mathrm{CO}_{2}(t), V_{1}(t), \mathrm{H}_{\mathrm{in} 1}, \mathrm{H}_{\mathrm{in} 2}\right\}, \\
& Y_{\mathrm{C}}^{\prime}(t+1)=\operatorname{LSSVM}_{2}\left\{T(t), \mathrm{S}_{\mathrm{C}}(t), \mathrm{H}_{I}(t),\right. \\
& \mathrm{N}(t), \mathrm{O}(t), \mathrm{GF}(t), \mathrm{CO}(t), \\
& \left.\mathrm{CO}_{2}(t), V_{1}(t), \mathrm{H}_{\mathrm{in} 1}, \mathrm{H}_{\mathrm{in} 2}\right\} \text {, } \\
& T(t)=\operatorname{LSSVM}_{1}\left\{T(t-1), \mathrm{S}_{\mathrm{C}}(t-1),\right. \\
& \mathrm{H}_{I}^{\prime}(t-1), \mathrm{N}^{\prime}(t-1), \mathrm{O}^{\prime}(t-1), \\
& \mathrm{GF}(t-c), \mathrm{CO}(t-c), \mathrm{CO}_{2}(t-c), \\
& \left.V_{1}^{\prime}(t-1), \mathrm{H}_{\mathrm{in} 1}, \mathrm{H}_{\mathrm{in} 2}\right\} \text {, } \\
& \mathrm{S}_{\mathrm{C}}(t)=\operatorname{LSSVM}_{2}\left\{T(t-1), \mathrm{S}_{\mathrm{C}}(t-1), \mathrm{H}_{I}^{\prime}(t-1)\right. \text {, } \\
& \mathrm{N}^{\prime}(t-1), \mathrm{O}^{\prime}(t-1), \\
& \mathrm{GF}(t-c), \mathrm{CO}(t-c), \\
& \left.\mathrm{CO}_{2}(t-c), V_{1}^{\prime}(t-1), \mathrm{H}_{\mathrm{in} 1}, \mathrm{H}_{\mathrm{in} 2}\right\} \text {, }
\end{aligned}
$$

where the dynamic operation optimization model is built by taking the minimum deviation between the actual data (oven temperature and carbon content of the molten steel) and the reference data by the optimal control indicator as objective function (7). When $Y_{\mathrm{C}}^{\prime \prime}(t+1) \leq Y_{\mathrm{C}}(t+1), \xi=0$, if not $\xi=e^{Y_{\mathrm{C}}^{\prime \prime}(t+1)-Y_{\mathrm{C}}(t+1)}$. In constraint (13) the carbon content must not surpass the strict requirement value; $\mathrm{N}(t)_{\min }, \mathrm{N}(t)_{\max }$, respectively, represent minimum and maximum the feed rate of the auxiliary material and the allowable value; $\mathrm{N}(t)_{\min }$ and
$\mathrm{N}(t)_{\max }$, respectively; in constraint (12) the bottom blown gas flow must not surpass the strict requirement value, a bottom blown gas flow rate, and the minimum certain value of the maximum certain value; in constraint $(14), \mathrm{O}(t)_{\min }$ and $\mathrm{O}(t)_{\max }$ are the minimum allowed lance oxygen flow value and the maximum allowable flow rate; in constraint (15) the lance mode must not exceed the strict requirement value; constraint (10) shows the correction value temperature and carbon content of molten steel; in constraints (8) and (9), $Y_{T}(t+1)$ is the current molten steel temperature value and $Y_{C}(t+1)$ is the current molten steel carbon content value determined by dynamic optimization control indices; constraints (16) and (17) show the relationship between the state variables; constraints (18) and (19) are the current temperature and carbon content estimation equation. The time and weight of adding limestone, dolomite, and other auxiliary materials, the amount of blowing oxygen, bottom blowing gas at each moment, and the control mode of oxygen lance are regarded as control variables.

\section{The Proposed Optimization Algorithm}

5.1. Differential Evolution (DE). There are several versions of DE algorithm [23]. Based on the difference between the fitness values of individuals, Tang et al. [24] proposed a novel IDE algorithm with an individual-dependent mechanism to set control parameters and choose mutation operators for each individual in different stages of the searching process. Tang et al. [25] proposed an improved differential evolution algorithm with a real-coded matrix representation for each individual of the population, a two-step method for generating the initial population, and a new mutation strategy. The algorithm we proposed in this paper is based on the version of $\mathrm{DE} / \mathrm{best} / 2 / \mathrm{bin}$. The algorithm is presented as follows.

In every generation of $\mathrm{DE}$, a population of $n_{p}$ candidate solutions is maintained, where each solution can be seen as a control vector in a $D$-dimensional continuous search space. The population is evolved and improved generation by generation. In generation $G$, we denote the $i$ th individual of the population as $X_{i, G}, i=1, \ldots, n_{p}$. Through the mutation operator and crossover operator, a new population is generated, the individual of which is called trial vector. A selection operator is used to decide which one to get into the next generation, parent or offspring. The evolution process moves on until a termination criterion is met. The details are presented as follows.

Mutation. In the version of $\mathrm{DE} / \mathrm{best} / 2 / \mathrm{bin}$, the mutation operation can be described as follows: the two weighted differential vectors obtained from the current population are added to the third vector which is the best individual having the best fitness value. At generation $G$, through the perturbation of four individuals selected randomly and the best individual $X_{\text {Best, }}$, the mutation individual $V_{i, G}$ is generated as follows:

$$
V_{i, G}=X_{\mathrm{Best}, G}+F *\left(X_{r_{1}, G}-X_{r_{2}, G}\right)+F *\left(X_{r_{3}, G}-X_{r_{4}, G}\right),
$$


TABLE 1: The training set and the testing set for multistage temperature models and carbon content models.

\begin{tabular}{|c|c|c|c|c|c|}
\hline \multicolumn{3}{|c|}{ Temperature } & \multicolumn{3}{|c|}{ Carbon content } \\
\hline Stage $/{ }^{\circ} \mathrm{C}$ & The training set & The testing set & Stage/\% & The training set & The testing set \\
\hline $1540-1560$ & 100 & 10 & $0.30-0.20$ & 100 & 10 \\
\hline $1560-1580$ & 100 & 10 & $0.20-0.10$ & 100 & 10 \\
\hline $1580-1600$ & 100 & 10 & $0.11-0.10$ & 100 & 10 \\
\hline $1600-1620$ & 200 & 10 & $0.10-0.09$ & 100 & 10 \\
\hline $1620-1640$ & 200 & 20 & $0.09-0.08$ & 100 & 10 \\
\hline $1640-1660$ & 100 & 10 & $0.08-0.07$ & 100 & 10 \\
\hline $1660-1680$ & 100 & 10 & $0.07-0.06$ & 100 & 10 \\
\hline $1680-1700$ & 100 & 10 & $0.06-0.05$ & 100 & 10 \\
\hline \multirow[t]{2}{*}{ 1700-final } & 40 & 10 & $0.05-0.04$ & 100 & 10 \\
\hline & & & 0.04 -final & 60 & 10 \\
\hline
\end{tabular}

where $i=1, \ldots, n_{p}$ and the randomly selected indices $r_{1}, r_{2}$, $r_{3}$, and $r_{4}$ belong to the integer set $\left\{1, \ldots, n_{p}\right\}$ and satisfy the expression $r_{1} \neq r_{2} \neq r_{3} \neq r_{4} \neq i$. In addition, $F$ is the scale factor and $F \in[0,1]$.

Crossover. After the mutation operation, the trial individual $U_{i, G+1}=\left(u_{1, i, G+1}, \ldots, u_{D, i, G+1}\right)$ is generated from the target individual $X_{i, G+1}=\left(x_{1, i, G+1}, \ldots, x_{D, i, G+1}\right)$ and the mutation individual $V_{i, G+1}=\left(v_{1, i, G+1}, \ldots, v_{D, i, G+1}\right)$ through the crossover operation described as follows:

$$
u_{j, i, G+1}= \begin{cases}v_{j, i, G+1}, & \text { if } \text { rand }_{j} \leq \mathrm{CR} \text { or } j=k, \\ x_{j, i, G+1}, & \text { otherwise }\end{cases}
$$

where $j=1, \ldots, D, k$ is a random vector's index, and $k \epsilon$ $\{1, \ldots, D\}$. In addition, the crossover rate $c_{r}$ is in the interval $[0,1]$.

Selection. In a competition way relying on the fitness value, we select one between the target individual and trail individual, which will survive and get into the next generation. For the minimization problem, the selection rule is expressed as follows:

$$
X_{i, G+1}= \begin{cases}U_{i, G+1}, & \text { if } f\left(U_{i, G+1}\right)<f\left(X_{i, G}\right), \\ X_{i, G}, & \text { otherwise, }\end{cases}
$$

where $F$ and $c_{r}$ are the control parameters and affect the performance of the algorithm largely.

5.2. Modified Differential Evolution. To increase the diversity of the population, we modify the mutation scheme. In our modified DE, we add a random factor $R$ subject to uniform distribution to increase the diversity and $R \in[0,1]$, so the mutation individual can be rewritten as follows:

$$
\begin{aligned}
V_{i, G}= & X_{\text {Best }, G}+F *\left(X_{r_{1}, G}-X_{r_{2}, G}\right) \\
& +(F+R) *\left(X_{r_{3}, G}-X_{r_{4}, G}\right) .
\end{aligned}
$$

The steps are given as follows.
Step 0. Set $k=1$.

Step 1. Generate the initial population $n_{p}=400$.

Step 2. Initialization of parameters: set the current number of iterations.

Initialize the variation factor $F=0.7$ and cross factor $c_{r}=$ 0.2 . Set the maximum number of iterations as $G_{\max }=100$. Set the current iteration number as $G=0$.

Step 3. Evaluation of the initial population is given as follows. The solution of best fitness is the current best solution $X_{\text {Best }}$.

Step 4. Mutation and crossover are demonstrated as follows. Use the mutation operator to get test vectors $U_{i, G+1}$ :

$$
u_{j, i, G+1}= \begin{cases}v_{j, i, G+1}, & \text { if } \operatorname{rand}_{j} \leq c_{r} \text { or } j=k, \\ x_{j, i, G+1}, & \text { otherwise, }\end{cases}
$$

where rand $_{j}$ is a random number in $[0,1]$.

Step 5. Generate a new population using population evaluation.

Update $X_{i}$ :

$$
X_{i, G+1}= \begin{cases}U_{i, G+1}, & \text { if } f\left(U_{i, G+1}\right)<f\left(X_{i, G}\right) \\ X_{i, G}, & \text { otherwise. }\end{cases}
$$

Compare a new solution $X_{i, G+1}$ with the best solution $X_{\text {best }}$; if $J\left(X_{\text {best }}\right)>J\left(X_{i, G+1}\right)$, then update $X_{\text {best }}=X_{i, G+1}$.

Step 6. If $G<G_{\max }$, return to Step 4 and set $G=G+1$; otherwise, stop iteration and output the optimal solution $X_{\text {best }}$.

Step 7. If $k<n$, return to Step 1 and set $k=k+1$; otherwise, stop. 


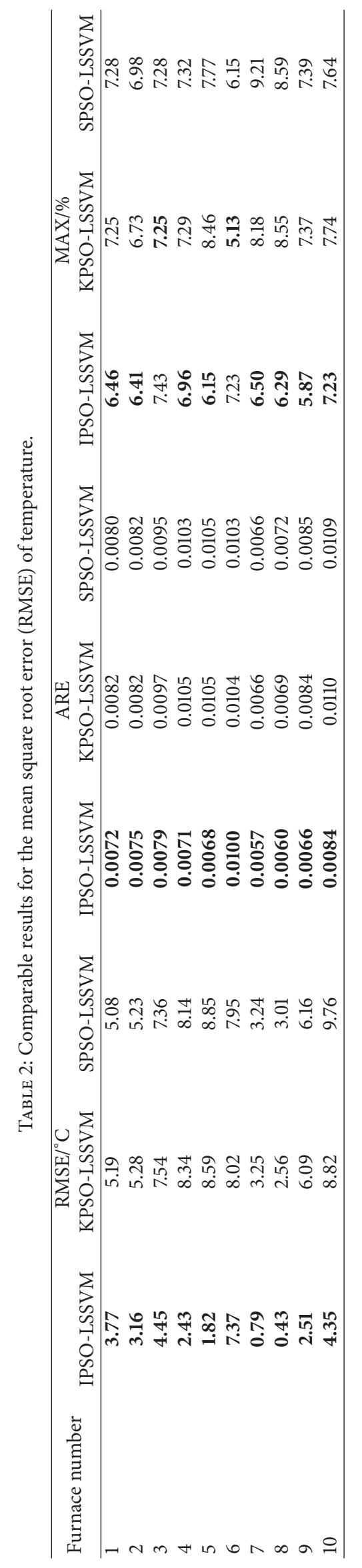




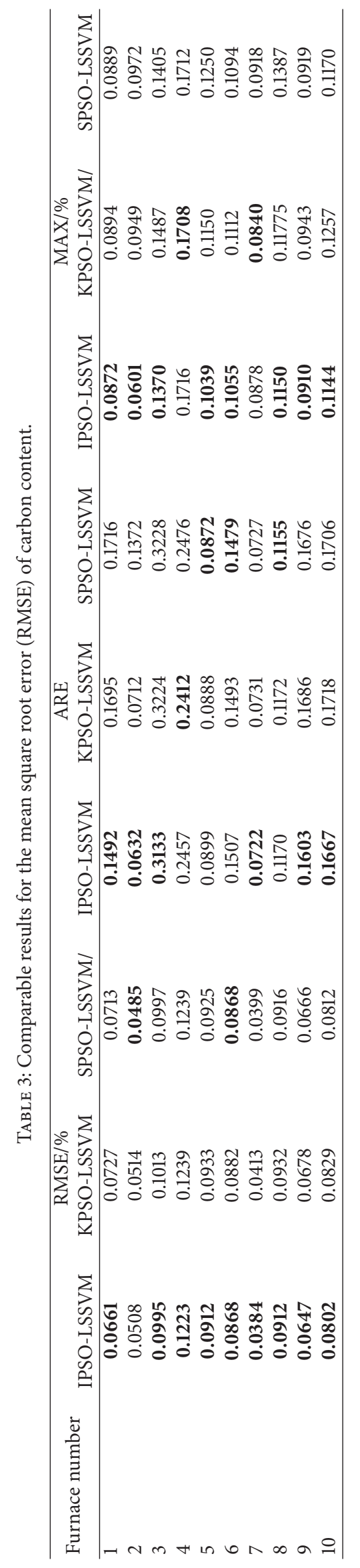


TABLE 4: Comparable results for the minimum function values of some algorithms.

\begin{tabular}{lccc}
\hline Model & DE/best/2/bin & jDE & SaDE \\
\hline 1 & $\mathbf{0 . 0 0 5 3}$ & $\mathbf{0 . 0 0 5 3}$ & $\mathbf{0 . 0 0 5 3}$ \\
2 & $\mathbf{0 . 0 1 3 5}$ & 0.0136 & 0.0138 \\
3 & $\mathbf{0 . 0 1 7 4}$ & 0.0175 & 0.0176 \\
4 & $\mathbf{0 . 0 0 8 0}$ & $\mathbf{0 . 0 0 8 0}$ & $\mathbf{0 . 0 0 8 0}$ \\
5 & $\mathbf{0 . 0 0 7 2}$ & 0.0073 & 0.0073 \\
6 & $\mathbf{0 . 0 0 8 2}$ & 0.0083 & 0.0083 \\
7 & $\mathbf{0 . 0 0 8 3}$ & 0.0084 & 0.0084 \\
8 & $\mathbf{0 . 0 0 9 3}$ & $\mathbf{0 . 0 0 9 3}$ & 0.0096 \\
9 & $\mathbf{0 . 0 0 5 0}$ & 0.0051 & 0.0051 \\
\hline
\end{tabular}

\section{Simulations and Discussion}

To illustrate the proposed method, the real industrial data are used for evaluating the performance of dynamic operation optimization model, and they are, respectively, obtained from experiment and engineering application. In this paper, the experiment is to dynamically set the value of each operating variable for the dynamical control of the temperature and carbon content in the molten steel. The method is coded in $\mathrm{C}++$ and run on a PC with $2.83 \mathrm{GHz}$ CPU (Core 2) and $3.25 \mathrm{~GB}$ memory using Windows XP operating system (32-bit).

6.1. The Result of Dynamic Prediction. The experiments of temperature and carbon content are done after clustering. Table 1 shows the training set and the testing set for temperature and carbon content models. We established dynamic models of temperature and carbon content by the final output parameters $\sigma, \gamma$, and $\alpha_{i}, i \in[0,1, \ldots, N]$, of IPSO-LSSVM. After establishing the model of temperature and carbon content, new 10 furnace data are regarded as the dynamic testing data set. Though dynamic temperature and carbon content models have some difficulties in the accuracy for whole furnaces, the model only depends on data instead of time. The model still shows the adaptive capability. In order to demonstrate the superiority, this paper compares IPSO-LSSVM with KPSO-LSSVM and SPSO-LSSVM [26, 27]. Tables 2 and 3 , respectively, show comparable results for three kinds of performance indices. We can find that the predicted error of IPSO-LSSVM is lower than that of the other two methods, and results show that IPSO-LSSVM has a better performance.

6.2. The Result of Optimal Control Problem. In this section, the proposed DE/best/2/bin is compared with some evolutionary algorithms in the literature, such as jDE in [28] and $\mathrm{SaDE}$ in [29]. The population size of the other two algorithms is set to 400 for $D=100$ in $\mathrm{jDE}$ and SaDE.

The ultimate convergence values of these three algorithms for the dynamic optimal control problem of BOF steelmaking process are given in Table 4. After comparing the convergence value with the other two methods, we can find that the error is comparatively closed between jDE and SaDE. The error of $\mathrm{DE} /$ best/2/bin is lower than that in the other two
TABLE 5: The information of the current practical production.

\begin{tabular}{lc}
\hline State variables & Value \\
\hline The hot iron weight & $152460 \mathrm{~kg}$ \\
Scrap & $23437 \mathrm{~kg}$ \\
Sublance temperature & $1610^{\circ} \mathrm{C}$ \\
Sublance carbon content & $0.054 \%$ \\
Aim temperature & $1666^{\circ} \mathrm{C}$ \\
Aim carbon content (product) & $0.11 \%$ \\
Aim carbon content (actual) & $0.03 \%$ \\
Off-gas flow & $39 \mathrm{Nm}^{3} / \mathrm{min}$ \\
CO content of off-gas & $33.8 \%$ \\
$\mathrm{CO}_{2}$ content of off-gas & $56.4 \%$ \\
\hline
\end{tabular}

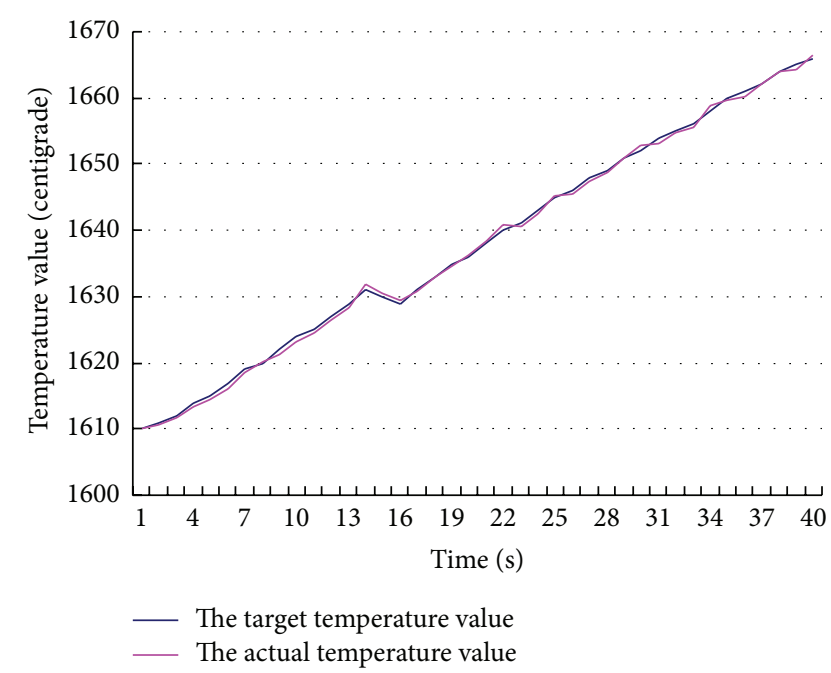

Figure 4: Dynamic curves between the actual temperature and the target temperature.

methods, and results show that $\mathrm{DE} /$ best/2/bin has a better performance.

The information of the current practical production is given in Table 5, from which we can find out that the temperature of molten steel should be heated up from $1610^{\circ} \mathrm{C}$ to $1666^{\circ} \mathrm{C}$. The carbon content of molten steel should be declined from $0.054 \%$ to $0.03 \%$.

Results of comparing between operating variables values of DE/best/2/bin with target value can be seen in Figures 68 and Table 6 . Figure 4 shows the target temperature and the actual value decided by operating variables values. Figure 5 shows the target carbon content and the actual value decided by operating variables values. The $x$-axis is blowing time; 0 represents the dynamic control starting moment which is the time getting the measurement results from sublance. Figure 9 shows the comparison between detection actual offgas flow and reference value of flue gas. Figure 10 shows the comparison between detection actual $\mathrm{CO}$ and $\mathrm{CO}_{2}$ content of flue gas and reference value. Table 7 shows the results for ARE, RMSE, and MAX of temperature and carbon content. Table 8 shows the endpoint value of temperature and carbon content. The experiment demonstrates that the performance 
TABLE 6: The calculated value of addition quantity and time of auxiliary material.

\begin{tabular}{|c|c|c|c|c|c|c|c|}
\hline $\begin{array}{l}\text { Time } \\
\text { (second) }\end{array}$ & $\begin{array}{l}\text { Auxiliary } \\
\text { material } 1\end{array}$ & $\begin{array}{c}\text { Auxiliary } \\
\text { material } 2\end{array}$ & $\begin{array}{c}\text { Auxiliary } \\
\text { material } 3\end{array}$ & $\begin{array}{c}\text { Auxiliary } \\
\text { material } 4\end{array}$ & $\begin{array}{c}\text { Auxiliary } \\
\text { material } 5\end{array}$ & $\begin{array}{c}\text { Auxiliary } \\
\text { material } 6\end{array}$ & $\begin{array}{l}\text { Auxiliary } \\
\text { material } 7\end{array}$ \\
\hline 0.6 & 0 & 0 & 0 & 0 & 0 & 0 & 0 \\
\hline 1.8 & 0 & 0 & 0 & 0 & 0 & 0 & 0 \\
\hline$\vdots$ & $\vdots$ & $\vdots$ & $\vdots$ & $\vdots$ & $\vdots$ & $\vdots$ & $\vdots$ \\
\hline 28.2 & 0 & 0 & 0 & 0 & 0 & 0 & 0 \\
\hline 30 & 303 & 0 & 0 & 0 & 0 & 0 & 0 \\
\hline 31.8 & 0 & 0 & 0 & 0 & 0 & 0 & 0 \\
\hline$\vdots$ & $\vdots$ & $\vdots$ & $\vdots$ & $\vdots$ & $\vdots$ & $\vdots$ & $\vdots$ \\
\hline 91.8 & 0 & 0 & 0 & 0 & 0 & 0 & 0 \\
\hline
\end{tabular}

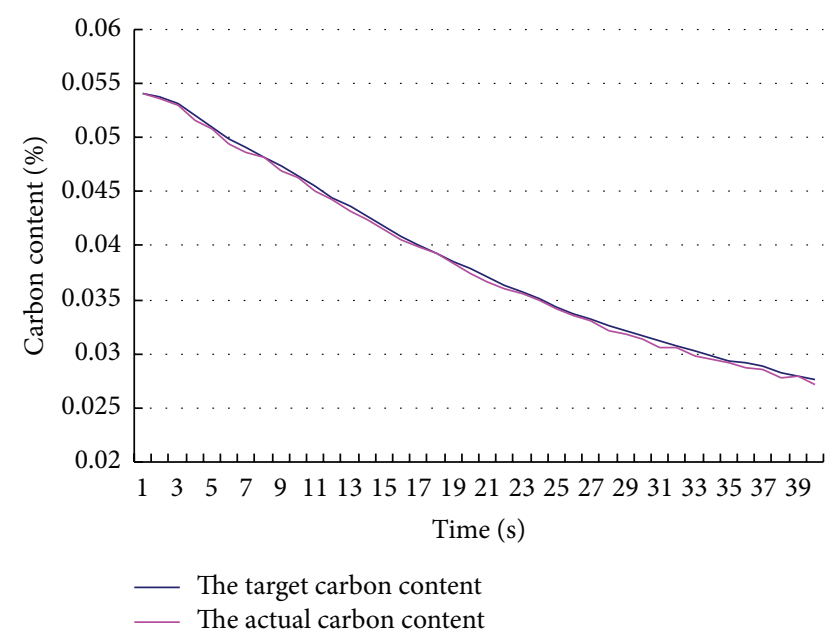

Figure 5: Dynamic curves between the actual carbon content and the target carbon content.

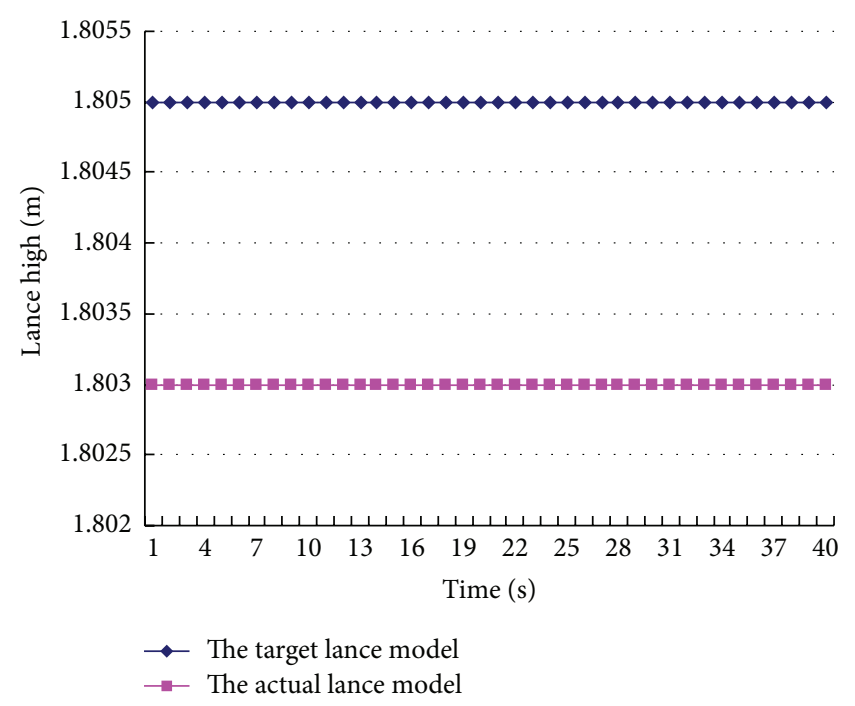

Figure 6: Dynamic curves between the actual lance mode and the target lance mode.
TABLE 7: The results for ARE, RMSE, and MAX of temperature and carbon content.

\begin{tabular}{lcc}
\hline Model & Temperature & Carbon content \\
\hline ARE & 0.4629 & 0.001127 \\
RMSE & 0.5330 & 0.008361 \\
MAX & 0.8423 & 0.002470 \\
\hline
\end{tabular}

TABLE 8: The endpoint values of temperature and carbon content.

\begin{tabular}{lcc}
\hline Model & Temperature & Carbon content \\
\hline Aim endpoint & $1666^{\circ} \mathrm{C}$ & $0.03 \%$ \\
Actual endpoint & $1666.047^{\circ} \mathrm{C}$ & $0.0074 \%$ \\
\hline
\end{tabular}

of the dynamic operation optimization method has a good adaptability.

\section{Conclusion}

This paper provides a dynamic operation optimization method for operating a converter to solve an optimal control problem. A classification method based on clustering and a LSSVM method is used in the paper. A real-time multiobjective operation optimization model is built by taking the minimum deviation between the actual data (oven temperature and carbon content of the molten steel) and the reference data by the optimal control indicator as objective function. An efficient algorithm for multiobjective operation optimization model is proposed to realize the optimal control problem for converter, directly improving the endpoint hit rate and improving the steel quality, as well as helping improve the overall productivity.

\section{Conflict of Interests}

The author declares that there is no conflict of interests regarding the publication of this paper. 


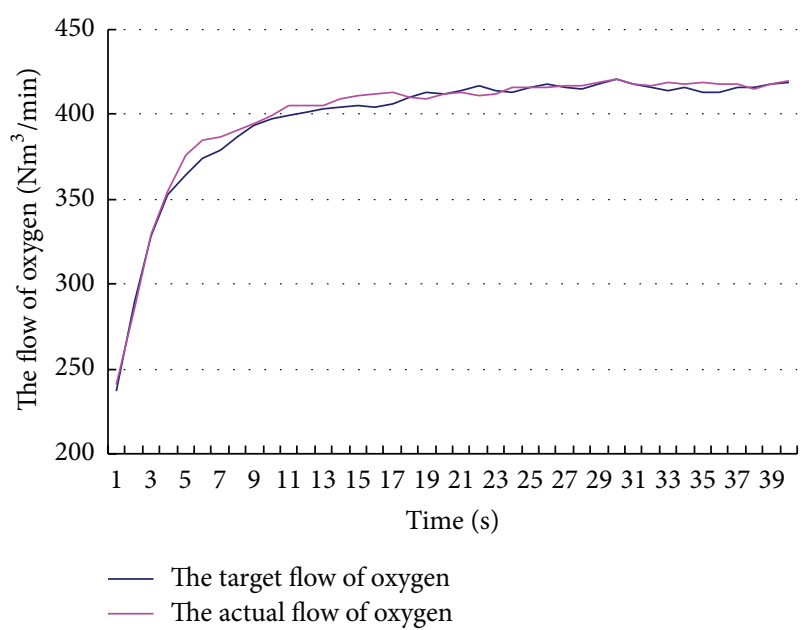

Figure 7: Dynamic curves between the actual flow and the target flow of oxygen.

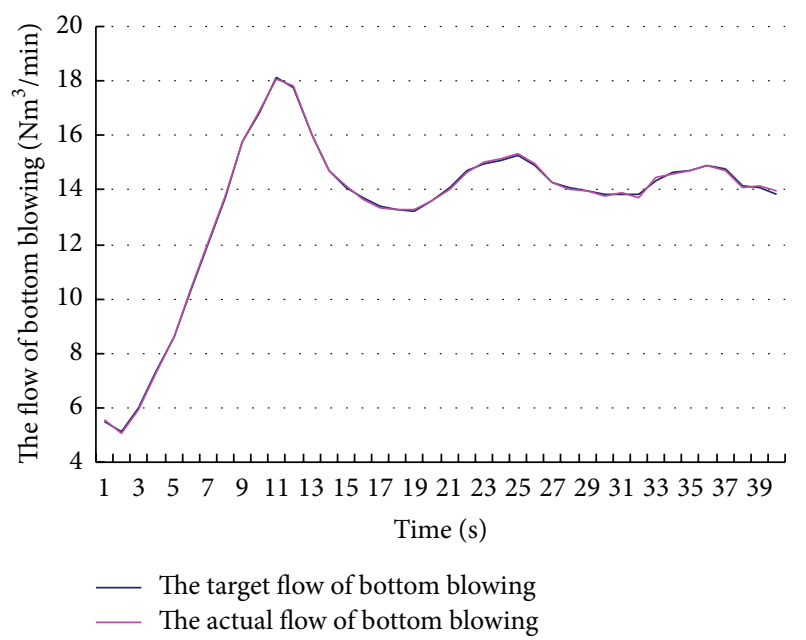

Figure 8: Dynamic curves between the actual flow and the target flow of bottom blowing.

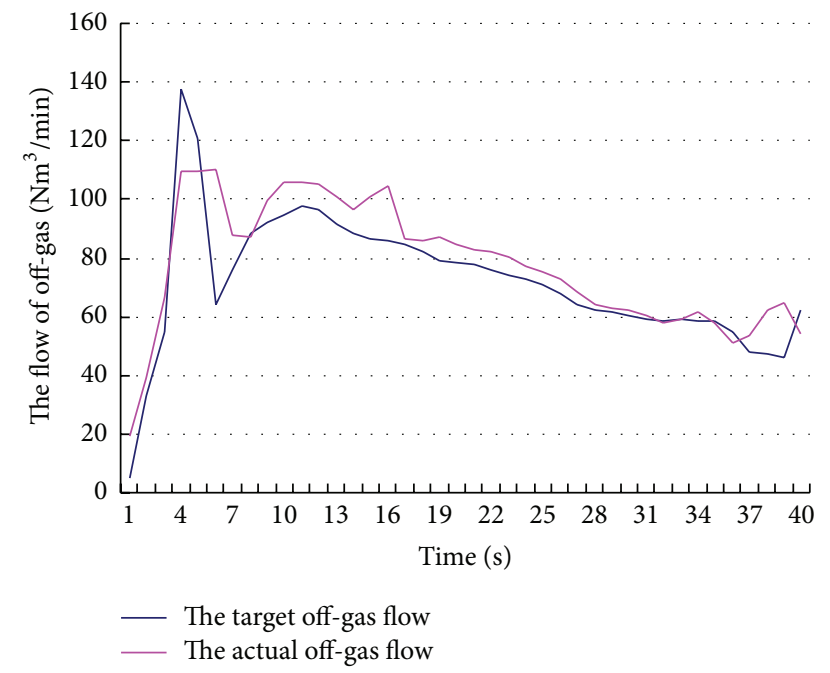

Figure 9: Comparison between detection actual off-gas flow and reference value of off-gas.

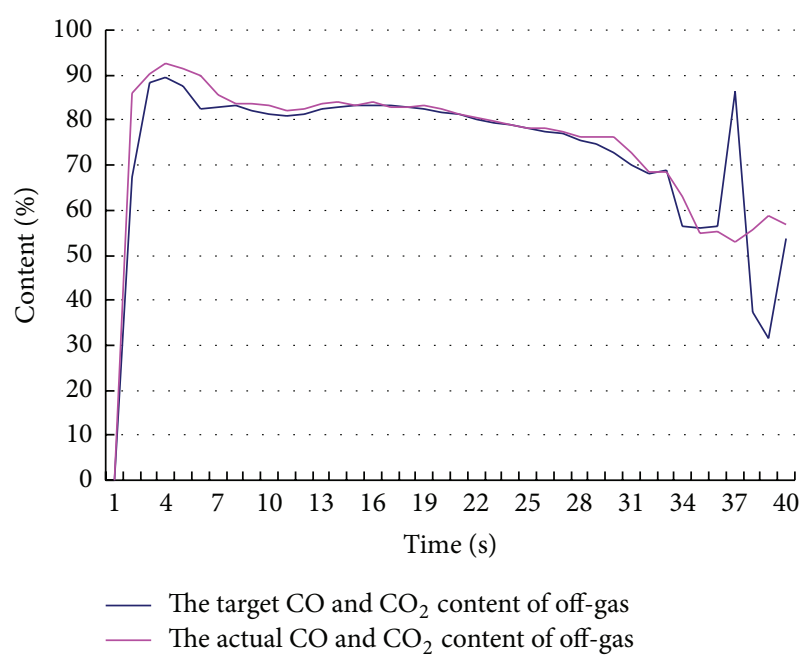

Figure 10: Comparison between detection actual $\mathrm{CO}$ and $\mathrm{CO}_{2}$ content of off-gas and reference value.

\section{Acknowledgment}

This research is partly supported by State Key Laboratory of Synthetical Automation for Process Industries Fundamental Research Funds (Grant no. 2013ZCX04-01).

\section{References}

[1] T. E. Marlin and A. N. Hrymak, "Real-time operations optimization of continuous processes," AIChE Symposium Series, vol. 316, pp. 156-164, 1997.

[2] W. S. Yip and T. E. Marlin, "Multiple data sets for model updating in real-time operations optimization," Computers and Chemical Engineering, vol. 26, no. 10, pp. 1345-1362, 2002.

[3] N. Peters, M. Guay, and D. DeHaan, "Real-time dynamic optimization of batch systems," Journal of Process Control, vol. 17, no. 3, pp. 261-271, 2007.

[4] V. Adetola and M. Guay, "Integration of real-time optimization and model predictive control," Journal of Process Control, vol. 20, no. 2, pp. 125-133, 2010.

[5] L. A. Alvarez and D. Odloak, "Robust integration of real time optimization with linear model predictive control," Computers and Chemical Engineering, vol. 34, no. 12, pp. 1937-1944, 2010.

[6] G. de Souza, D. Odloak, and A. C. Zanin, "Real time optimization (RTO) with model predictive control (MPC)," Computers and Chemical Engineering, vol. 34, no. 12, pp. 1999-2006, 2010.

[7] S. Ochoa, J.-U. Repke, and G. Wozny, "Integrating real-time optimization and control for optimal operation: application to the bio-ethanol process," Biochemical Engineering Journal, vol. 53, no. 1, pp. 18-25, 2010.

[8] M. C. Wellons, A. V. Sapre, A. I. Chang, and T. L. Laird, "Online power plant optimization improves Texas refiner's bottom line," Oil and Gas Journal, vol. 92, no. 20, pp. 53-58, 1994.

[9] A. M. Eliceche, N. C. Petracci, P. Hoch, and E. A. Brignole, "Optimal operation of an ethylene plant at variable feed conditions," Computers and Chemical Engineering, vol. 19, no. 1, pp. 223-228, 1995. 
[10] N. Petracci, A. M. Eliceche, A. Bandoni, and E. A. Brignole, "Optimal operation of an ethylene plant utility system," Computers and Chemical Engineering, vol. 17, pp. 147-152, 1993.

[11] Z. J. Shao, J. L. Wang, and J. X. Qian, "Real-time optimization of acetaldehyde production process," Developments in Chemical Engineering and Mineral Processing, vol. 13, no. 3-4, pp. 249-258, 2005.

[12] J. Z. Lu, "Challenging control problems and emerging technologies in enterprise optimization," in Proceedings of the 6th IFAC Symposium on Dynamic and Control of Process Systems, pp. 2334, Jejudo Island, Republic of Korea, June 2001.

[13] D. Bonvin and B. Srinivasan, "On the role of the necessary conditions of optimality in structuring dynamic real-time optimization schemes," Computers and Chemical Engineering, vol. 51, pp. 172-180, 2013.

[14] L. T. Biegler, "Technology advances for dynamic real-time optimization," Computer Aided Chemical Engineering, vol. 27, pp. $1-6,2009$.

[15] L. Tang, G. Wang, and Z.-L. Chen, "Integrated charge batching and casting width selection at Baosteel," Operations Research, vol. 62, no. 4, pp. 772-787, 2014.

[16] L. Tang, J. Liu, A. Rong, and Z. Yang, "Mathematical programming model for scheduling steelmaking-continuous casting production," European Journal of Operational Research, vol. 120, no. 2, pp. 423-435, 2000.

[17] L. Tang, P. B. Luh, J. Liu, and L. Fang, "Steel-making process scheduling using Lagrangian relaxation," International Journal of Production Research, vol. 40, no. 1, pp. 55-70, 2002.

[18] L. Wu, C. N. Yang, M. X. You, X. K. Xing, and Y. Hu, "A temperature prediction model of converters based on gas analysis," Procedia Earth and Planetary Science, vol. 2, pp. 14-19, 2011.

[19] H.-Y. Wen, Q. Zhao, Y.-R. Chen, M.-C. Zhou, M. Zhang, and L.$\mathrm{F}$. Xu, "Converter end-point prediction model using spectrum image analysis and improved neural network algorithm," Optica Applicata, vol. 38, no. 4, pp. 693-704, 2008.

[20] L.-F. Xu, W. Li, M. Zhang, S.-X. Xu, and J. Li, "A model of basic oxygen furnace (BOF) end-point prediction based on spectrum information of the furnace flame with support vector machine (SVM)," Optik, vol. 122, no. 7, pp. 594-598, 2011.

[21] M. Han, Y. Li, and Z. Cao, "Hybrid intelligent control of BOF oxygen volume and coolant addition," Neurocomputing, vol. 123, pp. 415-423, 2014.

[22] L. Yu, "An evolutionary programming based asymmetric weighted least squares support vector machine ensemble learning methodology for software repository mining," Information Sciences, vol. 191, no. 15, pp. 31-46, 2012.

[23] R. Storn and K. Price, "Differential evolution-a simple and efficient heuristic for global optimization over continuous spaces," Journal of Global Optimization, vol. 11, no. 4, pp. 341-359, 1997.

[24] L. X. Tang, Y. Dong, and J. Y. Liu, "Differential evolution with an individual-dependent mechanism," IEEE Transactions on Evolutionary Computation, 2014.

[25] L. X. Tang, Y. Zhao, and J. Y. Liu, "An improved differential evolution algorithm for practical dynamic scheduling in steelmaking-continuous casting production," IEEE Transactions on Evolutionary Computation, vol. 18, no. 2, pp. 209-225, 2014.

[26] K. E. Parsopoulos, D. K. Tasoulis, and M. N. Vrahatis, "Multiobjective optimization using parallel vector evaluated particle swarm optimization," in Proceedings of the IASTED International Conference on Artificial Intelligence and Applications, pp. 823-828, Innsbruck, Austria, February 2004.
[27] J. Liu, X. Ren, and H. Ma, "A new PSO algorithm with random C/D switchings," Applied Mathematics and Computation, vol. 218, no. 19, pp. 9579-9593, 2012.

[28] J. Brest, S. Greiner, B. Bošković, M. Mernik, and V. Zumer, "Self-adapting control parameters in differential evolution: a comparative study on numerical benchmark problems," IEEE Transactions on Evolutionary Computation, vol. 10, no. 6, pp. 646-657, 2006.

[29] A. K. Qin, V. L. Huang, and P. N. Suganthan, "Differential evolution algorithm with strategy adaptation for global numerical optimization," IEEE Transactions on Evolutionary Computation, vol. 13, no. 2, pp. 398-417, 2009. 


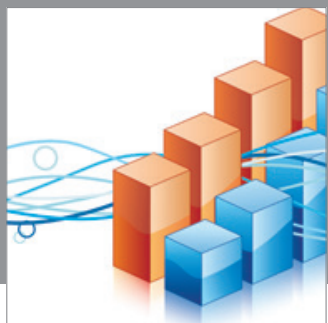

Advances in

Operations Research

mansans

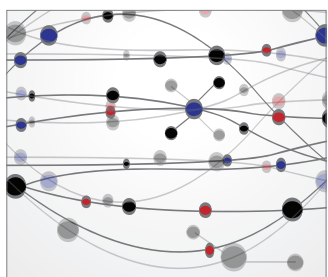

The Scientific World Journal
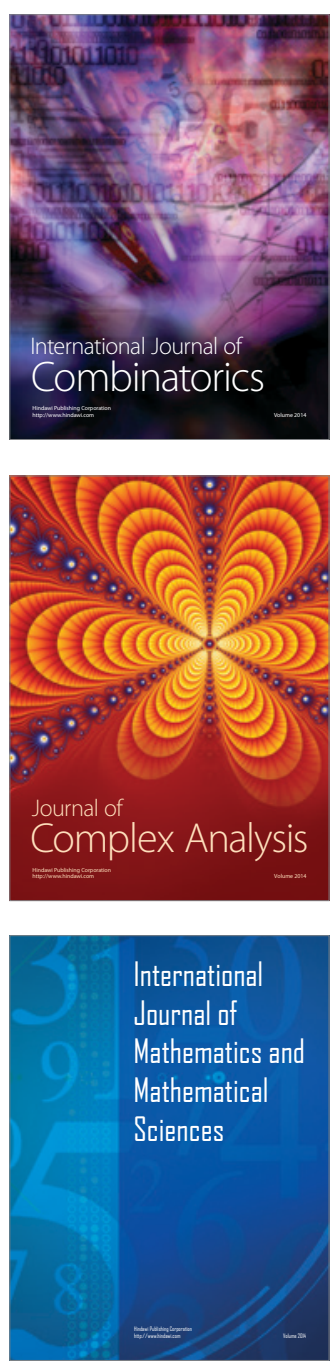
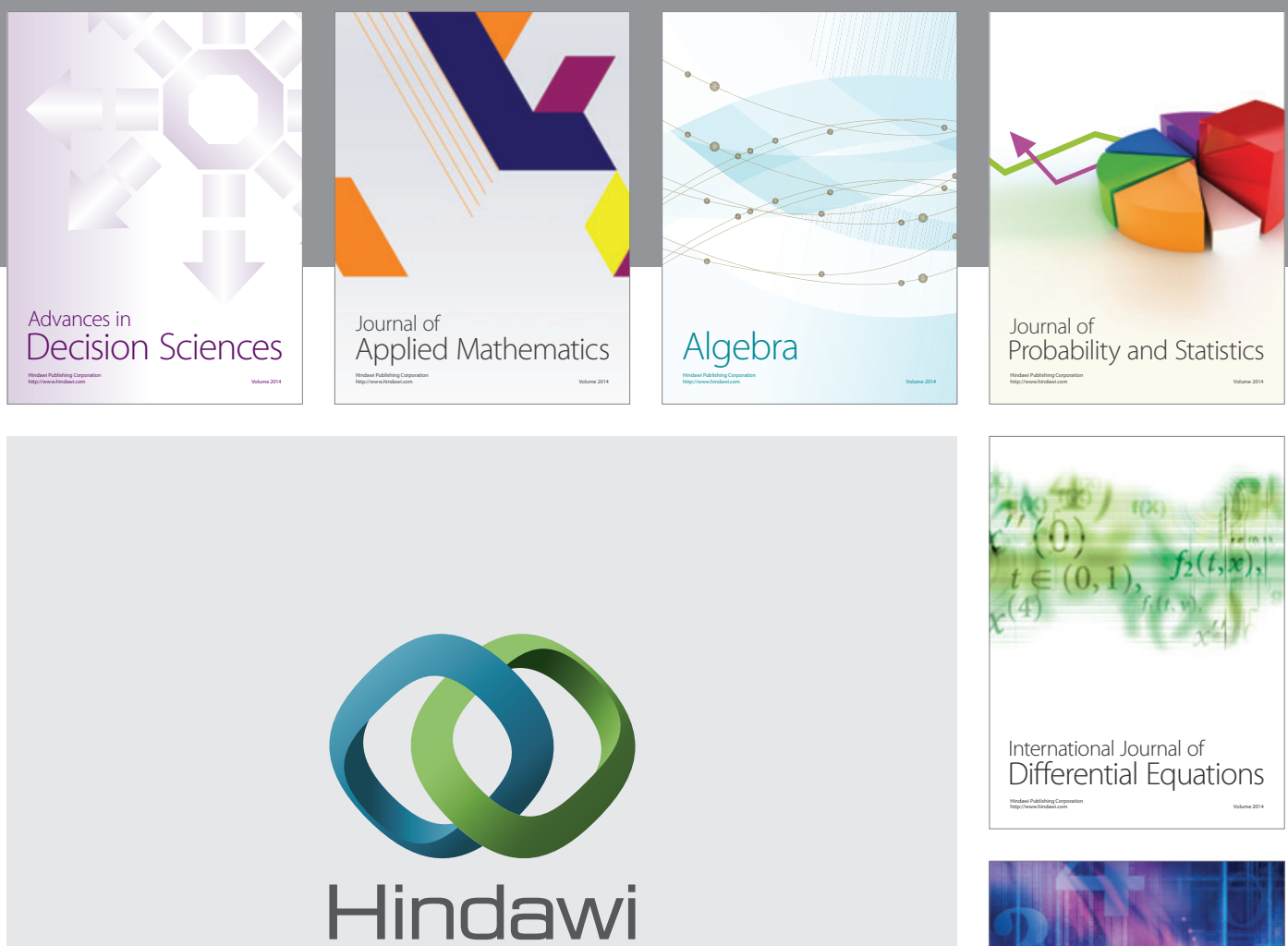

Submit your manuscripts at http://www.hindawi.com
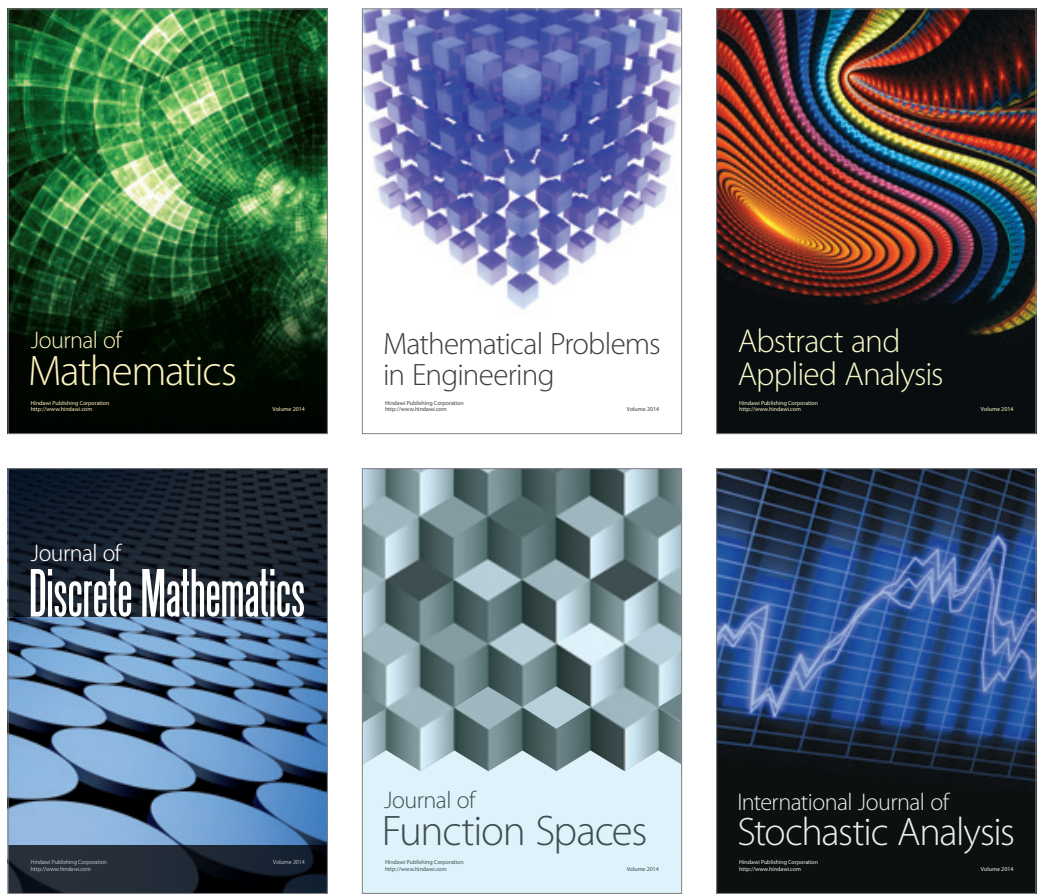

Journal of

Function Spaces

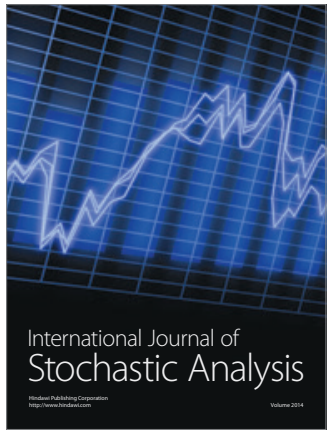

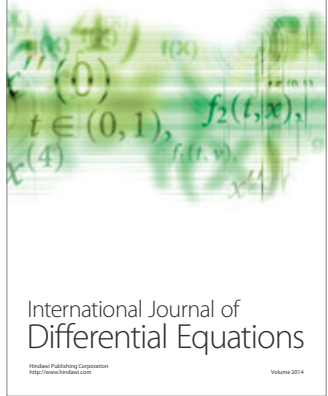
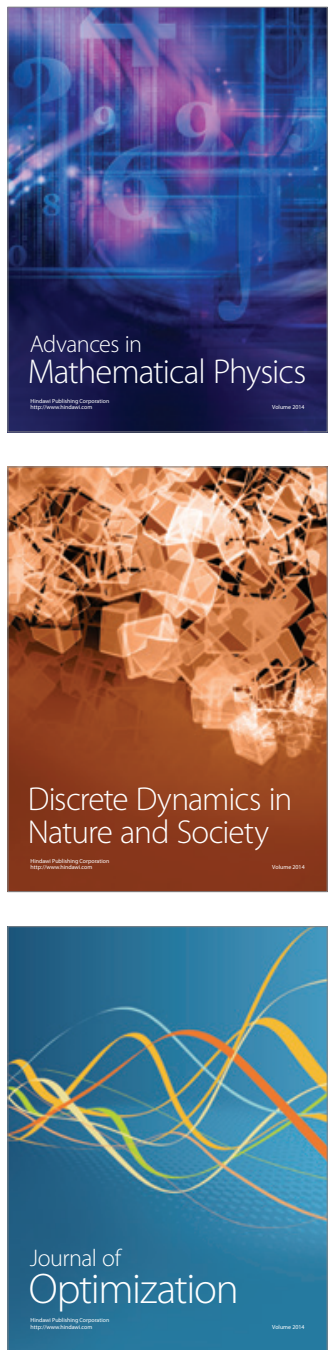